\title{
Frequency Support Properties of the Synchronous Power Control for Grid-Connected Converters
}

\author{
Weiyi Zhang ${ }^{1}$, Andrés Tarrassó ${ }^{2}$ \\ ${ }^{1} \mathrm{Xi}$ 'an University of Posts \& \\ Telecommunications \\ Xi'an 710121, China \\ zhangweiyi@xupt.edu.cn \\ daniel.remon@estudiant.upc.edu
}

\author{
Joan Rocabert ${ }^{2}$, Alvaro Luna ${ }^{2}$, \\ Ignacio Candela ${ }^{2}$ \\ ${ }^{2}$ Technical University of Catalonia \\ 08222 Barcelona, Spain \\ rocabert@ee.upc.edu \\ luna@ee.upc.edu \\ candela@ee.upc.edu
}

\author{
Pedro Rodriguez ${ }^{3,2}$ \\ ${ }^{3}$ Loyola Universiy of Andalucia \\ 41014 Seville, Spain \\ prodriguez@uloyola.es
}

\begin{abstract}
Grid-connected converters that integrate primary frequency support and inertia emulation functionalities have emerged in the last years. These features are promising for renewable power generation plants because it permits such systems to contribute to power system stabilization. This paper gives three different active power control solutions for gridconnected converters based on the Synchronous Power Control (SPC). For each solution, the detailed analytical relationship between the control parameters and the power loop dynamics is illustrated, and the local stability and dynamics are analyzed. The analysis and validation regarding the frequency support functionalities are particularly addressed in this work, where experimental test performed in a $10 \mathrm{~kW}$ experimental test bench have contributed to endorse the results that permits to conclude that the Synchronous Power Control offer a good performance in terms of inertial response and droop characteristics.
\end{abstract}

Index Terms--DC-AC power converter, Grid-Connected power converter, Power converter control, Synchronous Power Controller.

\section{INTRODUCTION}

The continuous penetration of renewables and the expansion of distributed generation plants, challenges the coordination and stabilization of the power system. Therefore, integrating generation and demand functionalities able to provide an automatic response in front of voltage and frequency distortions becomes a promising solution in the long run. In practice, only large power stations comprised of clusters of synchronous generators incorporate a droop mechanism for regulating their generated power as a function of the grid frequency variation. In order to provide frequency and voltage regulation from each interfaced terminal in modern electrical networks, renewable generation plants based on grid-connected converters are also required to interact with the grid and provide frequency and voltage support [1]. 
Most Distributed Generation (DG) systems are based on renewable energies, which can be combined with energy storage systems. These systems are increasingly required to participate in the grid regulation offering supporting services to improve the operation and stability of the grid. Due to this, the incoming standards for grid-connected power converter are more demanding regarding grid-supporting requirements. Hence, at the present time renewable based power generation systems cannot be based only in maximum power point tracking (MPPT) algorithms but droop characteristics should be also integrated. These droop functionalities are fully feasible from renewable energy sources in case of working with a capacity reserve or in parallel with any energy storage devices. Nowadays novel ancillary services, like synthetic inertia emulation, have started to be required in grid codes in order to improve the frequency stability and contribute to the inertial response. This approach give rise to a different paradigm if compared to the traditional definition of converter dynamics, which are characterized by the performance of the phase-locked loop (PLL) [2] and the power control that defines the operating references [3].

The idea of specifying grid-connected converters with inertia and droop characteristics is well accepted because of the successful operation of the traditional power system, which relies on the electromechanical characteristics of the numerous synchronous generators. As a result, the inertial response is required in new electrical codes and standards reproducing the performance of classical synchronous machines. In detail, the output impedance of a synchronous machine determines its electrical characteristics that leads to a natural load sharing and voltage droop, and the rotor inertia determines its mechanical characteristics that guarantees the healthy dynamics of the power system. Therefore, the control based on the characterization of the synchronous generator swing equations, mainly the emulation of the electro-mechanical characteristics, has been studied intensively in the past years ever since its first publication [4]. The studies have been conducted from different perspectives like inertia emulation characteristic [5]-[7], [8], PLLless control [9], providing virtual impedance [10], [11], adaptive inertial response [12], [13], primary frequency and voltage control [14], as well as stability analysis [15]-[16] where the impact of the droop coefficients and the virtual inertia impact on the system dynamics are analyzed .

The above mentioned works gave an insightful analysis or constructive implementation proposals on different aspects of synchronous generator emulation control, whereas the transient analysis and experimental validation in presence of grid frequency variations are not thoroughly shown. In the current literature, typical experimental verification scenarios for virtual synchronous power control include active and reactive power steps [4], [8-9], [13], [17-18], load changes [19-23], voltage sags [5], [13], [17], [23-26] and islanding [17-20] or [23]. However, the responses under grid frequency changes are not fully verified. Although the results shown in [12], [14], [21] have 
exhibited the frequency support effect under load changes, a quantitative transient relation between the grid frequency and the active power is not given and validated. Following the work [27], this paper introduces the synchronous power control (SPC) strategy for grid-connected converters to provide inertia emulation and primary frequency control. This validation is the main focus of this paper, based on the determination and analysis of the active power support over grid frequency variations for three different implementations of the electromechanic characteristics. Particularly, compared with existing studies, the transient response of the converters in presence of grid frequency changes is studied analytically and validated in experiments in this paper. The first implementation strategy, largely implemented in the literature, is based directly on the swing equation of the synchronous generator including the damping windings emulation. Based on the requirement to achieve a damped response in front of the ratio of change of frequency (ROCOF) characteristic from the swing equations implementation, two new damped response are suggested and analyzed. These are based on two damped transfer functions: PI and the lead-lag. In both cases the required attenuation and inertia constant are determined in order to achieve the desired response. In all the three cases the controlled gridconnected converter can give frequency support accurately following the specified dynamics, thus a good interaction between the converter and the grid is guaranteed.

One of the proposes achieved by these two new proposals to implement the emulation of the electromechanical characteristic is the decoupling between the droop parameter and the constant of inertia desired. This issue, which can be found in different virtual synchronous generation [28], hinders the design of the droop constants, especially in the case in which this parameter must be modified on-line to be adjusted to the grid conditions. Another of the problems detected is the power reference error in steady-state due to the droop slope in case of changes in the grid frequency. In [29] the droop is on-line modified, according with the ROCOF factor, in order to reduce the frequency deviation from the nominal value in microgrids. This change in the slope of the droop is restored once the frequency droop comes back to the nominal range.

\section{GRID-CONNECTED CONVERTERS BASED ON THE SPC}

The SPC endows grid connected voltage source converters (VSC) with virtual electromechanical characteristics, as an emulation and enhancement of synchronous generators [28], [31].

The electromechanical characteristics of synchronous generators can be split into two aspects, the stator output impedance (electrical) and the rotor inertia (mechanical). The former one defines the fundamentals of electrical interaction with the grid in terms of active and reactive power exchange, which also contributes to the grid 
synchronization, power sharing and unbalance compensation, etc. The latter one defines the power-frequency dynamics in power systems and contributes to the frequency stabilization.

The active and reactive powers transferred from e to $\mathrm{v}$ through a line with an impedance is defined as, [32]:

$$
\begin{gathered}
P=\frac{E V}{Z} \cos (\phi-\delta)-\frac{V^{2}}{Z} \cos (\phi), \\
Q=\frac{E V}{Z} \sin (\phi-\delta)-\frac{V^{2}}{Z} \sin (\phi),
\end{gathered}
$$

where $E$ and $V$ are the rms of $e$ and $v, Z \angle \phi$ the line impedance between the two sources, and $\delta$ the phase-angle difference between $e$ and $v$, and it is known as load-angle.

For common synchronous machines, considering a mainly inductive output impedance and the synchronized condition (a small value of $\delta$ ), (1) and (2) can be simplified as:

$$
\begin{gathered}
P=\frac{E V}{X} \delta=P_{\max } \delta, \\
Q=\frac{V(E-V)}{X} .
\end{gathered}
$$

As shown in (3) and (4), synchronous machines regulate the active and reactive powers by adjusting the load-angle and the magnitude of the electromotive force through the governor and the exciter, respectively. Similarly, the SPC controls the active and reactive powers by adjusting its inner voltage phase-angle and magnitude, respectively, in a similar way like a synchronous machine, rather than the conventional in-phase and in-quadrature current control performed in the decoupled rotating $(d-q)$ reference frame.

The overall control architecture for grid connected power converters based on the SPC and external droop controllers is shown in Fig. 1.

The power loop controller (PLC) and the virtual admittance determine the main characteristics of the SPC, which 
correspond to the mechanical and electrical part of synchronous machines, respectively.

\section{SYNCHRONOUS POWER LOOP CONTROL}

\section{EMBED Visio.Drawing.15}

Fig. 1. Grid-connected converters based on the Synchronous Power Controller (SPC).

The mathematical model of the active PLC of the SPC is shown in Fig. 2. The PLC is a generalized modeling of the active power control mechanisms based on the control structure of Fig. 1.

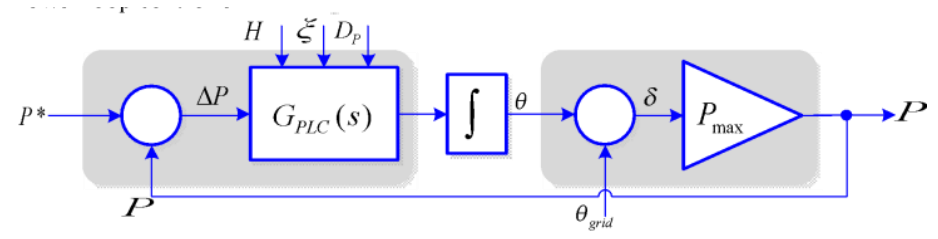

Fig. 2. Mathematical model of the SPC's active power control.

The synchronous angular speed $\omega$ is adjusted according to the error in the power converter's power balance regulation, which will further modify the load-angle $\delta$ to regulate generated active power. In this way, even though the grid voltage phase-angle $\theta_{\text {grid }}$ is unknown and can be variable in a realistic operation, $\omega$ can always be adjusted to eliminate the power control error, and meanwhile maintains the synchronization with the grid frequency $\omega_{g}$. GpLC $(s)$ represents the transfer function between the active power control error, $\Delta P$ is the difference between the power reference $\left(P^{*}\right)$ and the power injected in the point of common coupling (PCC), and $\omega$, and $P_{\max }$ is the gain between $\delta$ and the generated active power $P$, which is defined in (3).

The design of the SPC's PLC is discussed in this section based on the above modeling of the active PLC.

\section{A. Controller Based on the First-Order Torque Equation}

The synchronous machine first-order torque equation ( $1^{\text {st }}$ - OTE) for small signal variation of the rotor angular frequency, $\omega$, around the rated rotor angular frequency, $\omega_{s}$, can be expressed in terms of power as:

$$
P_{m}-P_{e}=\omega_{s}\left(J_{S}+D\right) \omega
$$

Based on the $1^{\text {st }}$ - OTE, the PLC in Fig. 2, GPLC $(s)$, could be implemented as shown in: 


$$
G_{P L C}(s)=\frac{1}{\omega_{s}\left(J_{s}+D\right)},
$$

which considers both the inertia, $J$, and the damping, $D$, terms. This transfer function is referred as the Mechanical PLC (MPL) in this paper. This simplified version of the active power loop control derived from the swing equation is utilized and analyzed in [29]-[30], as well as extended to dc systems [33].

According to (6), the resulting second-order closed-loop transfer function would have the following form:

$$
\frac{P}{P^{*}}(s)=\frac{\omega_{n}^{2}}{s^{2}+2 \xi \omega_{n} s+\omega_{n}^{2}}
$$

where:

$$
\begin{gathered}
\xi=\frac{D}{2} \sqrt{\frac{\omega_{s}}{J P_{\max }}}, \\
\omega_{n}=\sqrt{\frac{P_{\max }}{J \omega_{s}}},
\end{gathered}
$$

being $P_{\max }$ as defined in (3).

The MPL controller gains, $J$ and $D$, should be set according to:

$$
\begin{gathered}
J=\frac{2 H S_{N}}{\omega_{s}^{2}}, \\
D=\frac{2 \xi}{\omega_{s}} \sqrt{\frac{2 H S_{N} P_{\max }}{\omega_{s}}} .
\end{gathered}
$$

Taking the grid frequency, $\omega_{g}$, as an input variable and $P$ as the function output, the associated transfer function $(P-f$ response $)$ can be shown as:

$$
\frac{P}{\omega_{g}}(s)=\frac{-P_{\max }\left(s+2 \xi \omega_{n}\right)}{s^{2}+2 \xi \omega_{n} s+\omega_{n}^{2}},
$$

where $\omega_{n}$ and $\xi$ are given by (10) and (11), respectively.

By observing (12), it can be concluded that the MPL controller incorporates an intrinsic $P$ - $f$ droop characteristic. The interaction among the inertia $H$, the damping $\zeta$ and the per-unit $P$ - $f$ droop gain $R_{D}$ defined by the MPL controller can be written as:

$$
R_{D(M P L)}=\frac{1}{2 \xi} \sqrt{\frac{X_{p u}}{2 H \omega_{s}}},
$$


where $X_{p u}$ represents the per-unit value of the reactance of the virtual admittance

\section{B. PI Power Loop Controller}

The commonly used PI controller can also be used as an alternative to implement the PLC. The PI-based PLC makes the output regulated power equal to the reference value in steady state, even if there are variations in the grid frequency. In this way, a precise power tracking control can be simply achieved, without using any additional droop loop. Moreover, setting parameters for the external droop controller is straightforward and simple, since the power loop based on a PI controller does not have intrinsic droop. In addition, given values for the inertia and the damping characteristics can be guaranteed by properly setting the PI controller gains.

The PI controller used for the power loop has the following form:

$$
G_{P L C}(s)=K_{X}+\frac{K_{H}}{s}
$$

Using it as the power loop controller block in Fig. 2, the resulting closed-loop transfer function can be generically written as:

$$
\frac{\partial P}{\partial P_{r e f}}(s)=\frac{2 \xi \omega_{n} s+\omega_{n}^{2}}{s^{2}+2 \xi \omega_{n} s+\omega_{n}^{2}},
$$

where the damping coefficient and natural frequency are respectively given by:

$$
\begin{gathered}
\xi=\frac{K_{X}}{2} \sqrt{\frac{P_{\max }}{K_{H}}}, \\
\omega_{n}=\sqrt{P_{\max } K_{H}} .
\end{gathered}
$$

Therefore, the PI-based PLC gain, $K_{H}$, should be set according to:

$$
K_{H}=\frac{\omega_{n}^{2}}{P_{\max }} .
$$

The natural frequency, $\omega_{n}$, in this case, can be translated to the moment of inertia, $J$, by equating the $\omega_{n}$ in (9) and (17). Then (18) changes to:

$$
K_{H}=\frac{1}{J \omega_{s}},
$$

which changes to (20), expressed in terms of $H$.

$$
K_{H}=\frac{\omega_{s}}{2 H S_{N}}
$$


Substituting the $K_{H}$ in (16) using (20), the mechanism to set $K_{X}$ is obtained, expressed as:

$$
K_{X}=\xi \sqrt{\frac{2 \omega_{s}}{P_{\max } H S_{N}}} .
$$

The power response in presence of grid frequency changes will be given by:

$$
\frac{\partial P}{\partial \omega_{g}}(s)=\frac{-P_{\max } s}{s^{2}+2 \xi \omega_{n} s+\omega_{n}^{2}},
$$

from which, the steady-state droop gain is obtained as:

$$
D_{P}=\left|\frac{\partial P}{\partial \omega_{g}}(0)\right|=0
$$

It indicates that the power generated by the power converter will always track the power reference in steady state, regardless of whether the grid frequency changes or not.

According to (20) and (21), the control parameters $K_{X}$ and $K_{H}$ can be easily set from given values for $\xi$ and $H$.

\section{Lead-Lag Power Loop Controller}

Using a lead-lag controller for the active PLC, the direct implementation of the synchronous machine $1^{\text {st }}$ OTE is modified by adding a droop branch in parallel for controlling the $P$ - $f$ droop gain in steady state. In this way, this branch adjusts the offset of the power transfer function by introducing a new degree of freedom.

The transfer function of the proposed controller is generalized and written as:

$$
G_{P L C}(s)=\frac{K_{P} s+K_{I}}{s+K_{G}},
$$

which is referred as Configurable Natural Droop (CND) controller in this paper.

Compared with the MPL controller, the CND controller provides an additional degree of freedom without increasing the order of the power regulating transfer function. Moreover, it gives an inherent $P$ - $f$ droop feature, which can be configured independent to the inertia and damping parameters.

Substituting the PLC block in Fig. 2 by the expression (24), the resulting closed-loop transfer function can be written as:

$$
\frac{P}{P^{*}}(s)=\frac{\left(2 \xi \omega_{n}-K_{G}\right) s+\omega_{n}^{2}}{s^{2}+2 \xi \omega_{n} s+\omega_{n}^{2}}
$$

where the damping coefficient and natural frequency are expressed as: 


$$
\begin{gathered}
\xi=\frac{P_{\max } K_{P}+K_{G}}{2 \omega_{n}}, \\
\omega_{n}=\sqrt{P_{\max } K_{I}} .
\end{gathered}
$$

Therefore, the CND controller gain, $K_{I}$, should be set according to:

$$
K_{I}=\frac{\omega_{s}}{2 H S_{N}},
$$

The $P-f$ response of the CND controller is given by:

$$
\frac{P}{\omega_{g}}(s)=\frac{-P_{\max }\left(s+K_{G}\right)}{s^{2}+2 \xi \omega_{n} s+\omega_{n}^{2}},
$$

where (30) is obtained.

$$
D_{P(C N D)}=\frac{2 \pi K_{G}}{1000 K_{I}}
$$

The controller gain, $K_{G}$, should be set according to the inertia constant $H$ and the per-unit $P$ - $f$ droop gain $R_{D}$ by:

$$
K_{G}=\frac{1}{2 H R_{D}}
$$

Then the following expression is obtained:

$$
K_{P}=\xi \sqrt{\frac{2 \omega_{s}}{P_{\max } H S_{N}}}-\frac{1}{2 H R_{D} P_{\max }}
$$

by which the controller gain, $K_{P}$, can be set.

\section{STABILITY AND DyNAmics BASED ON DifFERENT POWER LOOP CONTROLLERS}

The stability of the active PLC and the power control dynamics are analyzed in this section, considering three different types of PLC mentioned in the last section.

\section{A. $\quad$ Stability Based on Different Power Loop Controllers}

The system based on the $1^{\text {st }}$ - OTE, (7), is a standard second-order system, which is known that its stability is determined by the closed-loop poles, accordingly, by $\xi$. Comparing (7), (15) and (25), all the three types of PLC lead to the same closed-loop poles, expressed by $\omega_{n}$ and $\xi$. Therefore, the stability is mainly determined by the value of $\xi$, no matter which PLC is used. However, since the PI and the lead-lag (LL) controllers introduce additional zero to the system, the phase-frequency characteristics can be slightly different based on different PLC, which may lead to different phase margins. 
Fig. 3 shows the Bode plot of the systems based on different PLC. Fig. 3(a), (b), (c) and (d) all show that the phase margin resulted from different PLC are close to each other. The only observed difference among different PLC is the crossover frequency, which mainly reflect the dynamic characteristics.

\section{EMBED Visio.Drawing.11 ।* MERGEFORMAT EMBED Visio.Drawing.11 ${ }^{*}$ MERGEFORMAT

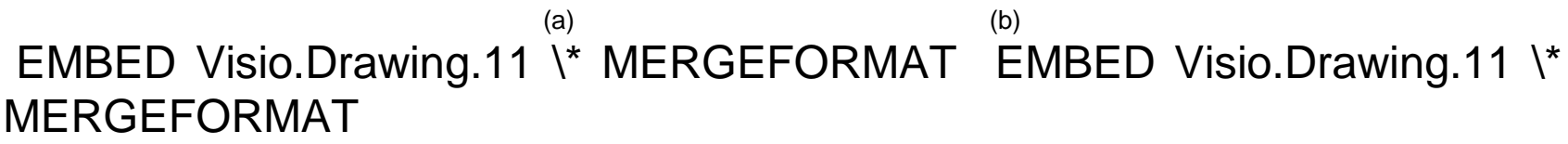 (c) \\ Fig. 3. Bode plot based on different power loop controllers and different parameter values: (a) $H=5 \mathrm{~s}, \zeta=0.3$, (b) $H=5 \mathrm{~s}, \zeta=0.7$, (c) $H$ $=10 \mathrm{~s}, \zeta=0.7$, (d) $H=5 \mathrm{~s}, \zeta=1.1$.}

\section{B. Dynamics Based on Different Power Loop Controllers}

Compared with the transfer function (7), the system based on the PI or lead-lag controllers, (15) or (25), has an additional zero. According to the control theory, an additional zero in a second-order system decreases the damping of the system, which may have two effects, faster speed and bigger overshoot. In order to evaluate the dynamics of the systems based on the PI and lead-lag controllers and compare them with the typical $1^{\text {st }}$ - OTE, the closed-loop magnitude-frequency characteristics are plotted, as Fig. 4 shows.

Fig. 4(a) shows that the systems based on different PLCs have similar bandwidth, under $\zeta=0.3$. It shows that when the system has an insufficient damping, the bandwidth will be largely determined by the damping, while the system zero introduced by the PI or lead-lag controller does not relatively affect it.

When the damping is increased, the effect of the system zero increases, which results in the bandwidth separation 
in different PLCs, as Fig. 4(b) shows. Under a proper damping factor $\zeta$, the systems based on the PI or lead-lag controllers have larger bandwidth than the system based on the $1^{\text {st }}$ - OTE, which will make the systems have faster speed.

Comparing Fig. 4(b) and (c), it can be seen the well-known fact that the dynamics of the second-order system is largely determined by the natural frequency, and further by the inertia constant of the PLC. When the inertia constant increases from 5 to $10 \mathrm{~s}$, the bandwidth of all the three systems decreases significantly.

Comparing Fig. 4(c) and (d), it can be seen another difference between the systems based on the PI or lead-lag controllers and the system based on the $1^{\text {st }}$ - OTE. For the former two systems, the bandwidth does not change much along with the damping factor $\zeta$, however, the bandwidth decreases for the latter one system.

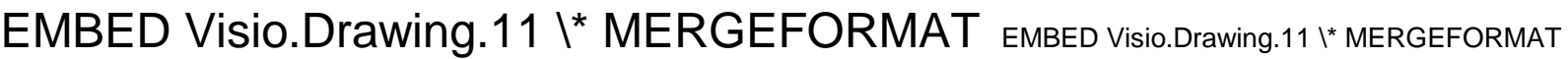 (a) (b) EMBED Visio.Drawing. $11 \backslash^{*}$ MERGEFORMAT EMBED Visio.Drawing. $11 \backslash^{*}$ MERGEFORMAT \\ (c) \\ (d) \\ Fig. 4. Closed-loop magnitude-frequency characteristics based on different PLC and different parameter values: (a) $H=5 \mathrm{~s}, \zeta=0.3$, (b) $H=5 \mathrm{~s}, \zeta=0.7$, (c) $H=10 \mathrm{~s}, \zeta=0.7$, (d) $H=5 \mathrm{~s}, \zeta=1.1$.}

Fig. 5 is plotted in order to demonstrate the relationship between the settling time and the inertia constant.

It is known that the settling time of a standard second-order system is inversely proportional to the natural frequency $\omega_{n}$, therefore, the settling time of the system based on the $1^{\text {st }}$ - OTE is proportional to the square root of the inertia constant $H$, according to (9) and (10). Fig. 5 demonstrates that the systems based on the PI or LL controllers follow a 
similar characteristic, as an emulation of the synchronous generator dynamics.

Fig. 5(a) shows that when $\zeta=0.7$, the settling time of the system based on the PI or lead-lag controller is smaller than the one based on the $1^{\text {st }}$ OTE. Fig. 5(b) shows that when $\zeta=0.8$, the situation is the opposite. Comparing Fig. 5(a) with (b), it is found that the settling time of the systems based on the PI or lead-lag controllers is not relatively affected by the change of the damping factor, while the settling time of the system based on the $1^{\text {st }}$ - OTE is more affected. Fig. 5 (c) shows that when $\zeta=0.9$, the three systems share a similar relationship between settling time and inertia constant.

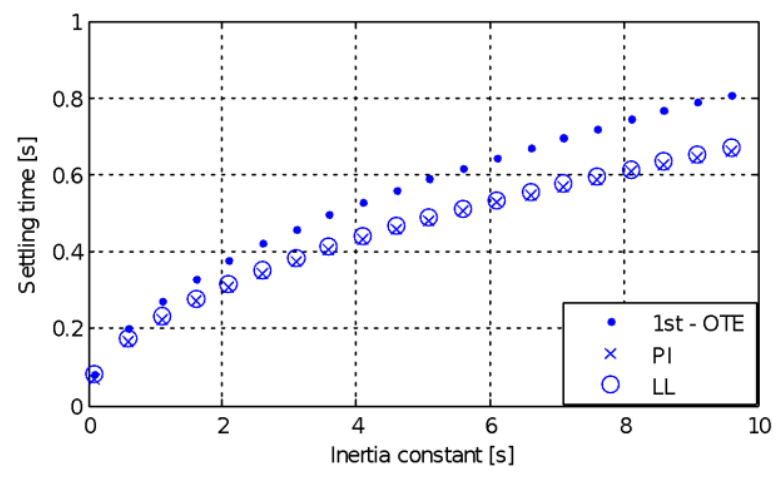

(a)

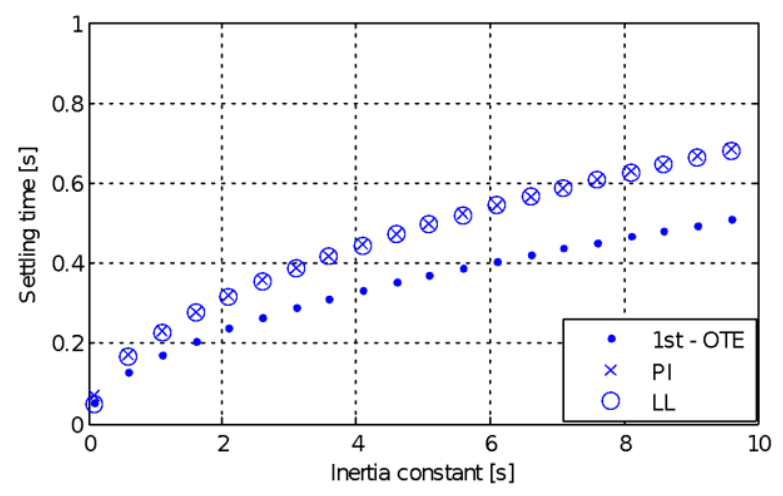

(b)

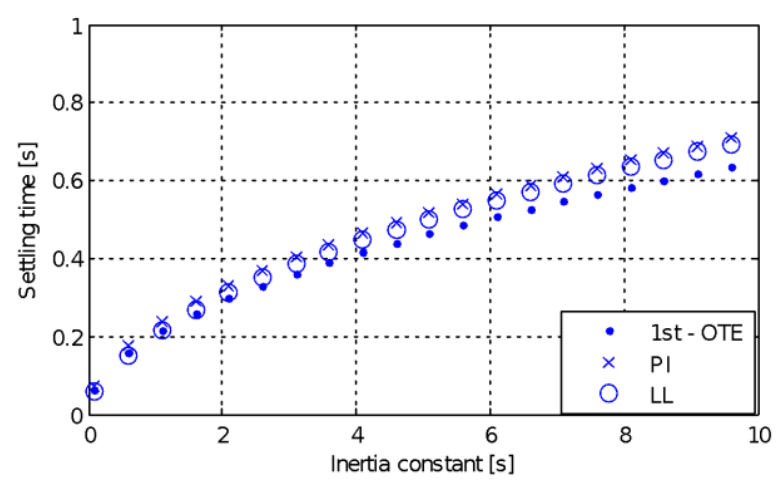


Fig. 5. Relationship between the inertia constant and the closed-loop step response settling time: (a) $\zeta=0.7$, (b) $\zeta=0.8$, (c) $\zeta=0.9$.

In order to further show the influence of the damping factor on the system settling time, for the systems based on different PLC, Fig. 6 is plotted.

It is found from Fig. 6 that in the value range $\zeta=\left[\begin{array}{ll}0.6 & 1\end{array}\right]$, the settling time of the systems based on the lead lag controller does not relatively change. However, in the value near $\zeta=0.63$, the settling time of the systems based on the PI controller has a fast change, and in the value near $\zeta=0.77$ (close to the theoretical value 0.707 ), the settling time of the systems based on the $1^{\text {st }}$ - OTE has a fast change. This point where the fast change occurs can be defined as the "sufficient damping" value. The damping value smaller than this value is not sufficient and causes too many oscillations before arriving the steady-state value, and hence increases the settling time, and on the other hand, the damping value bigger than it gives more than enough damping, and results in a slower response (also increases the settling time). It is obvious from Fig. 6 that the "sufficient damping" value for the lead lag controller is smaller than the other two strategies, and the $\zeta$ for $1^{\text {st }}-$ OTE has a stronger effect in controlling the settling time.
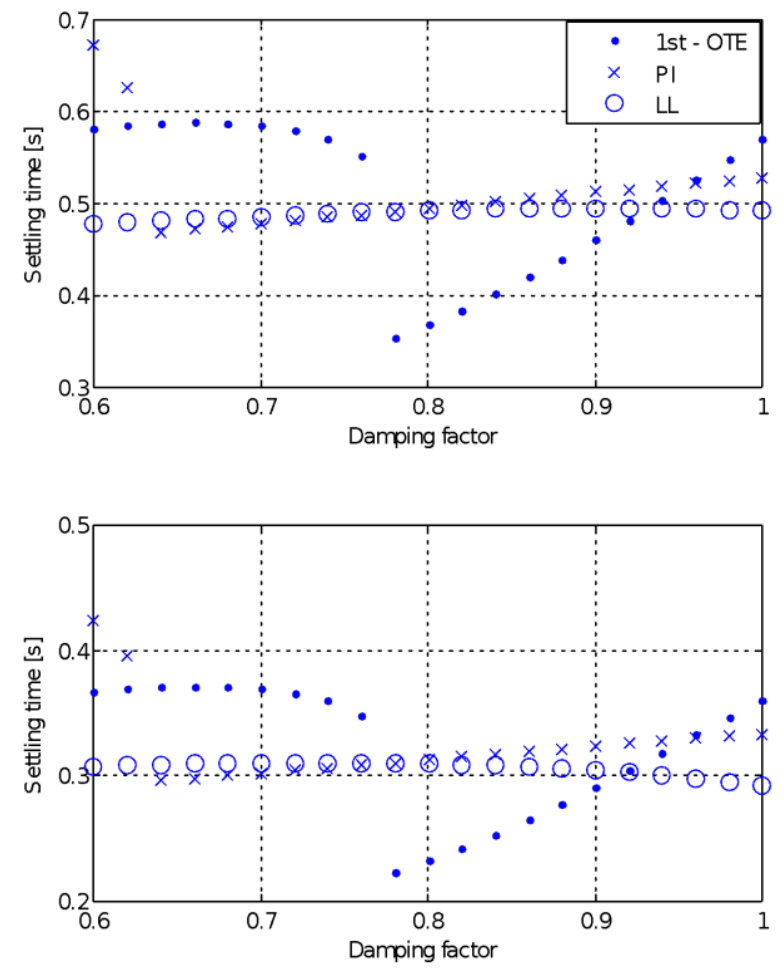

(a)

(b)

Fig. 6. Relationship between the damping factor and the closed-loop step response settling time: (a) $H=5 \mathrm{~s}$, (b) $H=2 \mathrm{~s}$. 
Fig. 7 shows the relationship of the system overshoot with the damping factor. It is demonstrated that for all the systems based on different PLC, the overshoot is always determined by the damping factor. However, under the same damping factor, the system based on the $1^{\text {st }}$ - OTE has the smallest overshoot, while the system based on the PI has the biggest one.
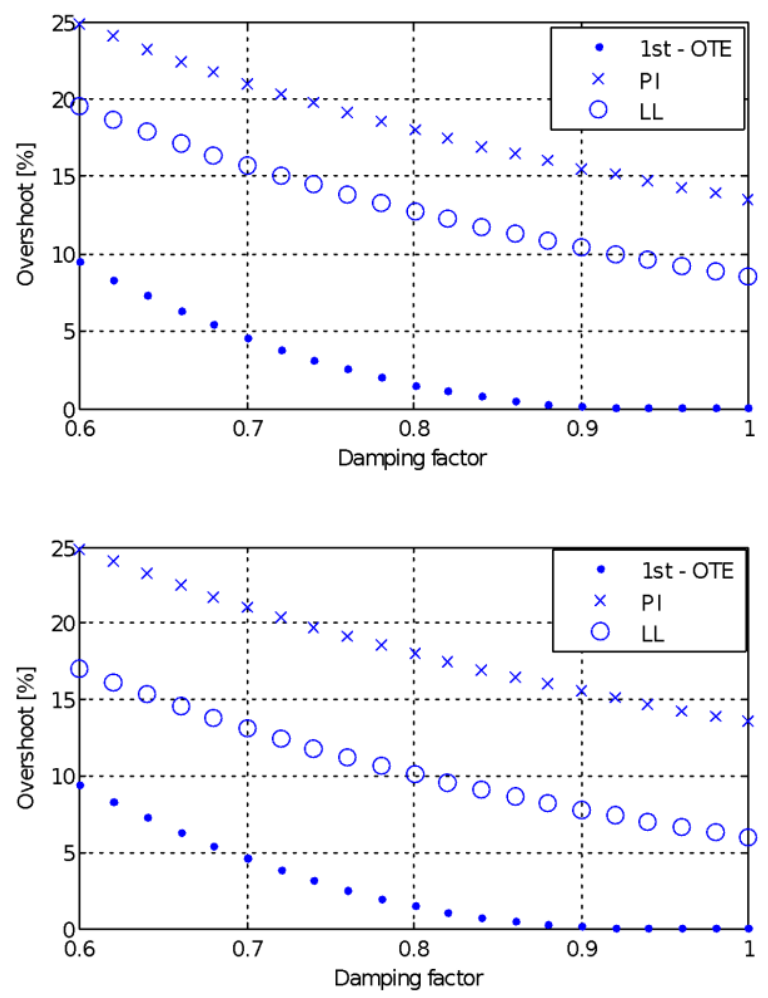

(a)

(b)

Fig. 7. Relationship between the damping factor and the closed-loop step response overshoot: (a) $H=5 \mathrm{~s}$, (b) $H=2 \mathrm{~s}$.

\section{EXPERIMENTAL RESULTS}

The experimental setups are shown in Fig. 8, where a $10 \mathrm{~kW}$ converter interacts with the grid that is formed by the regenerative power source California Instrument MX45. By using this ac source the grid voltage waveforms, magnitude and frequency are programmed, and hence the sweep of grid frequency can be generated. A $20 \mathrm{~kW}$ dc power source supplies the dc bus of the converter, and the control is implemented in dSPACE ds1103. The parameters 
are shown in Table I. The lead lag controller is choses as the power loop controller for experimental tests.

Table 1. Key experimental parameters for power loop controllers' validation

\section{EMBED Visio.Drawing. 15 (a) EMBED Visio.Drawing. 15}

Fig. 8. 10 kW grid connected power converter experimental setup: (a) block diagram, (b) laboratory view.

\begin{tabular}{lcc}
\hline Description & Symbol & Value \\
\hline grid phase-to-phase voltage & $V_{g}$ & $400[\mathrm{~V}]$ \\
grid nominal frequency & $f_{g}$ & $50[\mathrm{~Hz}]$ \\
dc bus voltage & $V_{D C}$ & $640[\mathrm{~V}]$ \\
power converter nominal power & $P_{N}$ & $10[\mathrm{~kW}]$ \\
switching frequency & $f_{s w}$ & $10050[\mathrm{~Hz}]$ \\
damping factor (if not & $\xi$ & $0.7[\mathrm{p} . \mathrm{u}]$. \\
mentioned) & & \\
virtual resistance & $R_{p u}$ & $0.1[\mathrm{p} . \mathrm{u}]$. \\
virtual reactance & $X_{p u}$ & $0.3[\mathrm{p} . \mathrm{u}]$. \\
\hline
\end{tabular}

\section{A. Experimental results compared to transfer function analysis and simulation}

Fig. 9 shows the transient active power response in the presence of a grid frequency sweep. Fig. 9(a) shows the programmed frequency sweep, where the ramp slope is $1 \mathrm{~Hz} / \mathrm{s}$. Fig. 9(b) shows the waveform for the grid voltage and current injected by the converter during the frequency sweep. It can be observed in this figure how the current is well controlled in steady state and exhibit a significant transient response to compensate the change of the grid frequency. It should be also noted how the converter presents a smoothed response during transients. 
Fig. 10(a) compares the response of active power obtained by transfer function response plotting, simulation and experimental test. In the three cases the controller works with the same set of parameters. The transfer function shown in (29) is used for this comparison. Fig. 10(a) shows a perfect response match from the three different cases. It validates how the transient response of the grid-connected converter in practice perfectly follows the dynamics of transfer function (29). In this way, the damping, inertia and droop characteristics can be accurately set and the feasibility of this controller is experimentally demonstrated. In this test, the $P$ - $f$ droop gain is set to $10 \%$. The measured active power delivered by the power converter takes a steady-state value of 0.56 p.u. when the grid frequency holds at $49.7 \mathrm{~Hz}$, and 0.44 p.u. when the grid frequency holds at $50.3 \mathrm{~Hz}$.

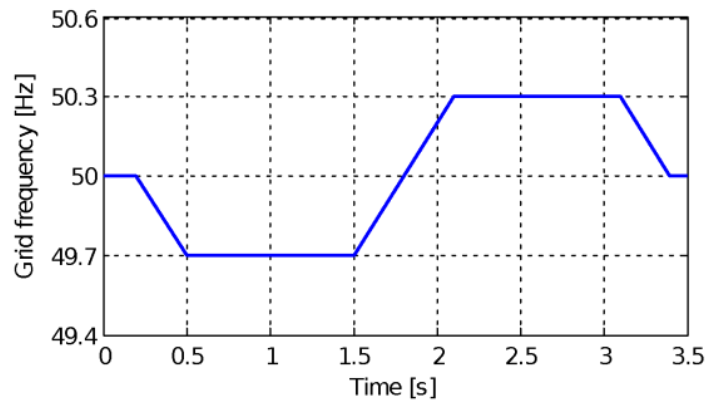

(a)
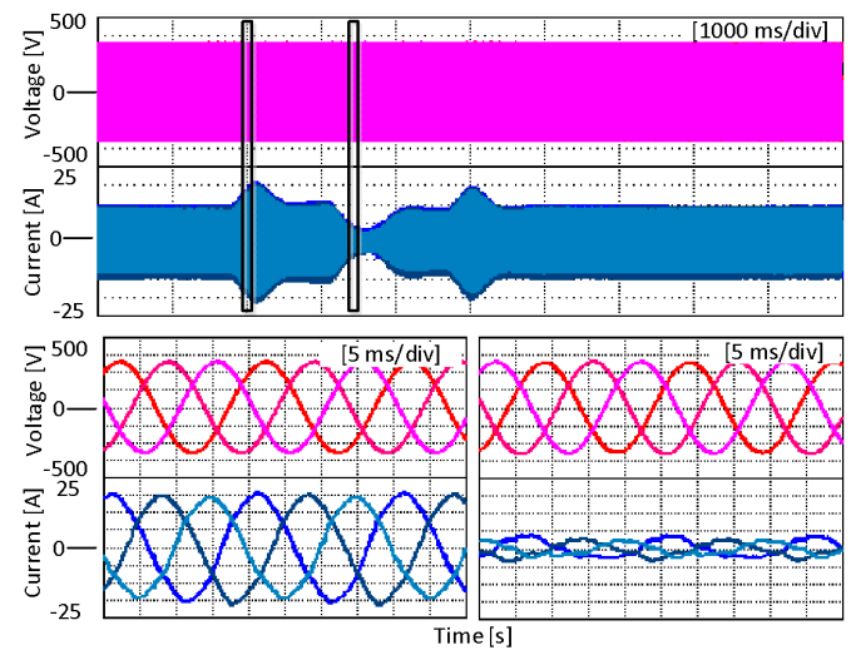

(b)

Fig. 9. Experimental result of the CND PLC under a grid frequency sweep: (a) grid frequency profile, and (b) grid voltage and injected current. 


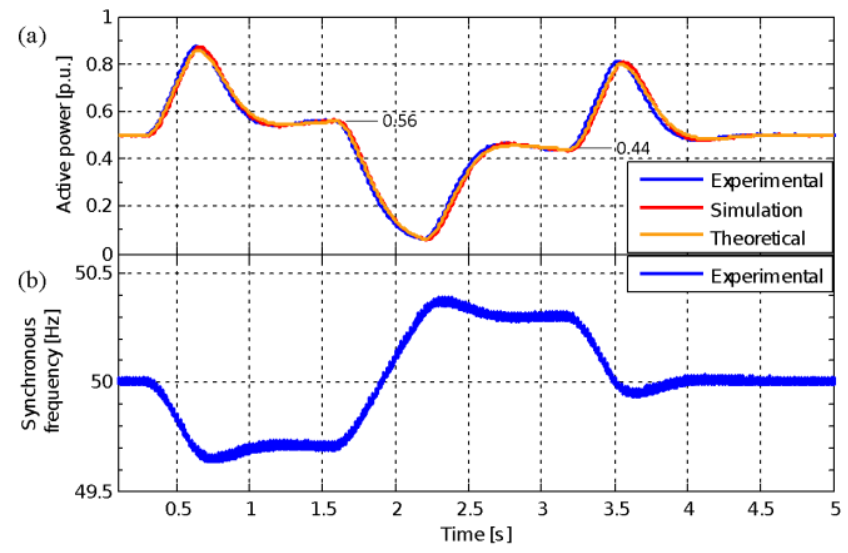

Fig. 10. Experimental result analysis of the CND PLC under a grid frequency sweep: (a) experimental active power response comparing with simulation and calculation, and (b) the inner virtual synchronous frequency of the experimental converter.

Fig. 10(b) shows the evolution of the virtual synchronous angular speed $\omega$. As appreciated in this figure, a high value for inertia constant $(H=10 \mathrm{~s})$ results in a long settling time in the grid frequency tracking, longer than the one in a traditional loop based on a PLL. The difference between $\omega$ and $\omega_{g}$ during the transient leads to a significant active power inertial response to compensate such a frequency deviation.

\section{B. Inertial and droop characteristics}

Fig. 11 shows the transient responses of the power converter when different values are set for the inertia constant $H$.

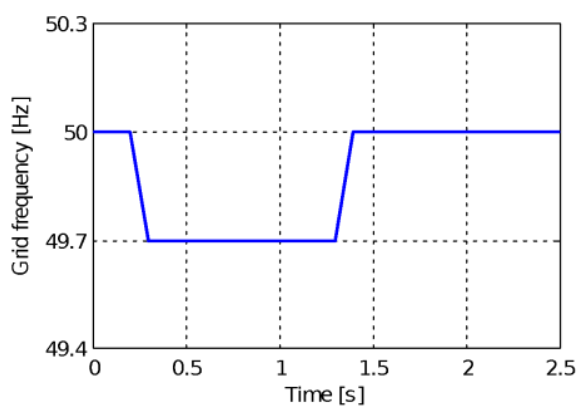

(a)

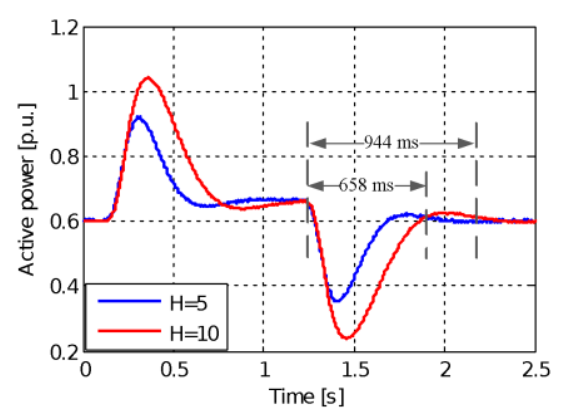

(b)

Fig. 11. Comparison of the active power transient responses of the CND PLC under a grid frequency sweep under different values of inertia constant: (a) grid frequency profile, and (b) comparison of active power responses.

The frequency profile that triggers the active power responses is shown in Fig. 11(a). The frequency ramp slope in this figure is $3 \mathrm{~Hz} / \mathrm{s}$. The initial operating point of the power converter is $6 \mathrm{~kW}$ and $0 \mathrm{kVar}$. The active power responses for two different inertia constant values, $H=5$ and $H=10$, is measured and shown in Fig. 11(b). The settling times 
for both values of $H$ in response to the frequency profile are $944 \mathrm{~ms}$ and $658 \mathrm{~ms}$. It is easy to calculate that $944 / 658=1.43 \approx \sqrt{10 / 5}$, which matches the relationship that the settling time is proportional to the square root of the inertia constant.

Fig. 12 shows the active power transient responses of the power converter when different values are set for the damping factor $\xi$. Fig. 12(a) shows the current injected by the power converter.
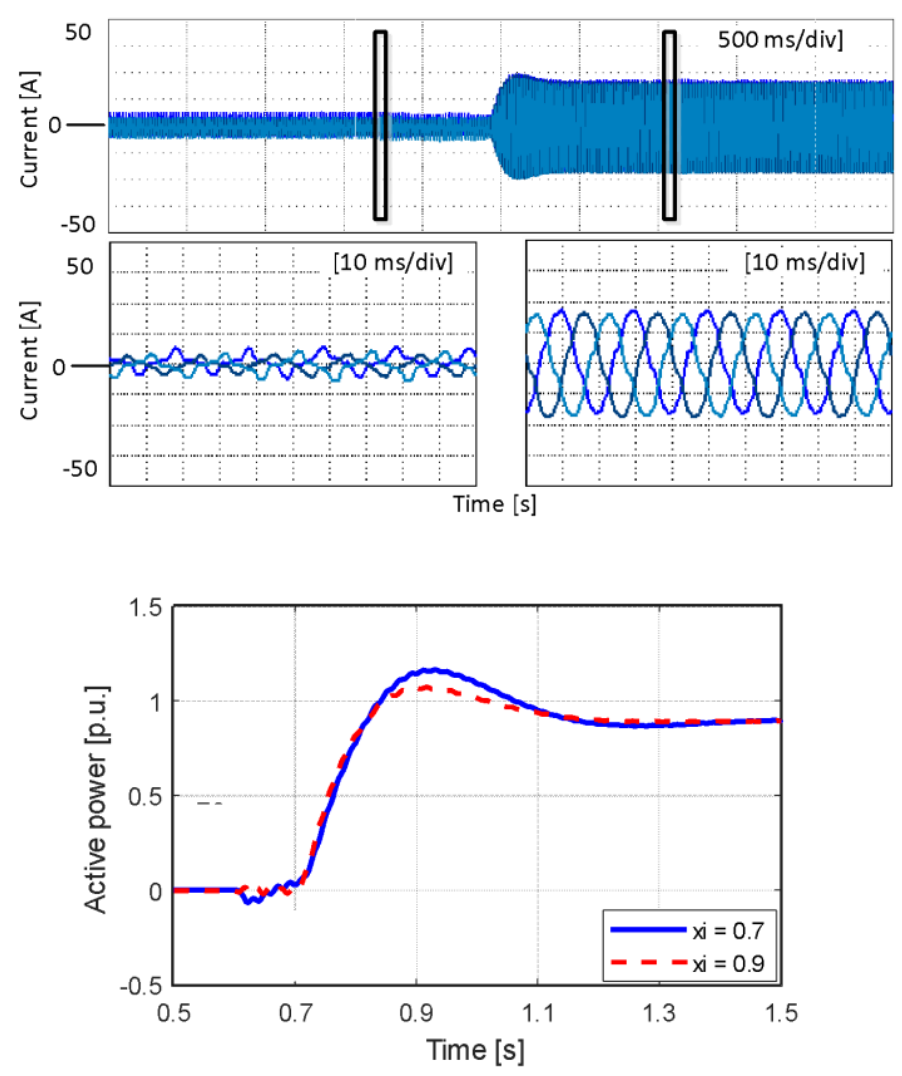

(a)

(b)

Fig. 12. Comparison of the active power transient responses of the CND PLC under a power reference step under different values of damping factor: (a) injected current, and (b) comparison of active power responses.

When the lead lag controller is used as the PLC, according to Fig. 6, the settling time does not change much along with the damping factor, and according to Fig. 7, the overshoot decreases when the damping factor increases. This theory is verified in experiment as Fig. 12(b) shows.

The droop characteristic of the power converter is shown in Fig. 13. The grid frequency variation is plotted in Fig. 13(a), where it decreases to $49.9 \mathrm{~Hz}$ during $0.1 \mathrm{~s}$, holds for $1 \mathrm{~s}$ and increases back to $50 \mathrm{~Hz}$ during $0.1 \mathrm{~s}$. In three simulation cases, the droop gain $R_{D}$ is set to infinite $\left(D_{P}=0\right), 10 \%$ and $5 \%$, corresponding to $0 \mathrm{~kW} / \mathrm{Hz}, 2 \mathrm{~kW} / \mathrm{Hz}$ and $4 \mathrm{~kW} / \mathrm{Hz}$, respectively. Fig. 13(b) shows the transient active power responses. It can be observed in this figure how 
the active power steady-state value after the first frequency ramp is 0.6 p.u., 0.62 p.u. and 0.64 p.u., respectively, according to the programmed droop gains.

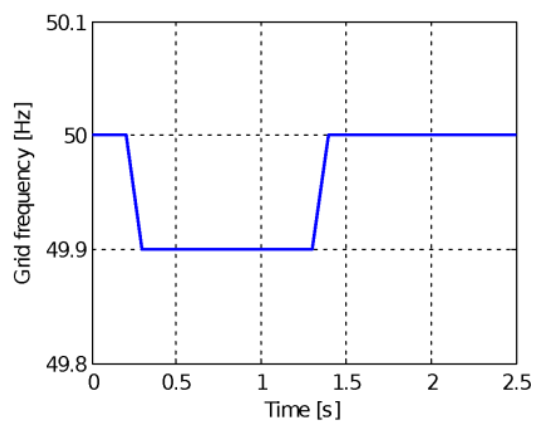

(a)

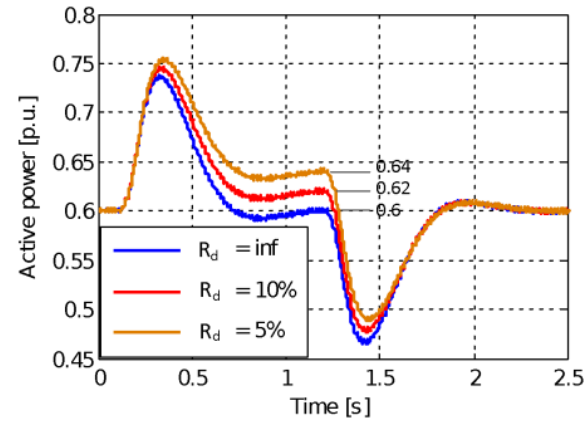

(b)

Fig. 13. Comparison of the active power transient responses of the CND PLC under a grid frequency sweep under different values of droop gain: (a) grid frequency profile, and (b) comparison of active power responses.

In summary, these experimental results verify the inertial, damping and droop response of the controller in case of grid frequency changes. The good matching in the transient active power responses obtained from the transfer function, the experimental results validates the effectiveness and the easy implementation of the previously presented controller.

\section{CONCLUSION}

This paper presented three different PLC strategies for grid-connected converters based on the Synchronous Power Controller, oriented to provide inertia emulation and primary frequency control features to power converters linked to renewable energy systems. The PLC was designed to provide damping, inertia emulation and $P$ - $f$ droop characteristics with considerations of stability and dynamics. The frequency support characteristics of the controlled converter were particularly analyzed and validated in this paper. The analytical relation between the grid frequency deviation and the active power change was derived based on the accurate modeling of the active PLC. The experimental tests, done in a $10 \mathrm{~kW}$ regenerative source test bed, equipped with a frequency programmable voltage ac-source, have endorsed the analytical analysis. In this regard, the inertia and droop characteristics were clearly shown scenarios where there is a frequency sweep tests and the converter is controlled with different sets of parameters. The simulation and experimental results validate the performance of the three models of PLC presented in this paper. Therefore, the inertia constant, damping factor and droop gain can be accurately given for achieving a good grid-interaction dynamics and also complying with the current TSO requirements. 



\section{REFERENCES}

[1] ENTSO-E, "ENTSO-E Network Code for Requirements for Grid Connection Applicable to All Generators”, 2013.

[2] R. Teodorescu, M. Liserre, and P. Rodriguez, Grid Converters for Photovoltaic and Wind Power Systems. John Wiley \& Sons, Ltd, 2011.

[3] H. Akagi, E. Hirokazu, and M. Aredes, Instantaneous power theory and applications to power conditioning. John Wiley \& Sons, Ltd, 2007.

[4] H. P. Beck and R. Hesse, "Virtual synchronous machine," in Proc. EPQU, 2007, pp. 1-6.

[5] M. P. N. Van Wesenbeeck, S. W. H. De Haan, P. Varela, and K. Visscher, "Grid tied converter with virtual kinetic storage," in IEEE Bucharest PowerTech, 2009, pp. 1-7.

[6] U. Tamrakar, D. Shrestha, M. Maharjan, and B. P. Bhattarai, "Virtual Inertia : Current Trends and Future Directions," Appl. Sci., vol. 7, no. 7, pp. 1-29, 2017.

[7] Q. C. Zhong and G. Weiss, "Synchronverters: Inverters that mimic synchronous generators," IEEE Trans. Ind. Electron., vol. 58, no. 4, pp. 1259-1267, 2011.

[8] Y. Du, J. M. Guerrero, L. Chang, J. Su, and M. Mao, "Modeling, analysis, and design of a frequency-droop-based virtual synchronous generator for microgrid applications," in 2013 IEEE ECCE Asia Downunder - 5th IEEE Annual International Energy Conversion Congress and Exhibition, IEEE ECCE Asia 2013, 2013.

[9] L. Zhang, L. Harnefors, and H. P. Nee, "Power-synchronization control of grid-connected voltage-source converters," IEEE Trans. Power Syst., vol. 25, no. 2, pp. 809-820, 2010.

[10] Y. Chen, R. Hesse, D. Turschner, and H. Beck, "Comparison of methods for implementing virtual synchronous machine on inverters," in Proc. ICREPQ, 2012, pp. 1-6.

[11] P. Rodriguez, I. Candela, C. Citro, J. Rocabert, and A. Luna, "Control of Grid-Connected Power Converters Based on a Virtual Admittance Control Loop," in Proc. EPE, 2013, pp. 1-10.

[12] M. A. Torres, L. A. Lopes, L. A. Moran, and J. R. Espinoza, "Self-Tuning Virtual Synchronous Machine: A Control Strategy for Energy Storage Systems to Support Dynamic Frequency Control," IEEE Trans. Energy Convers., vol. 29, no. 4, pp. 833-840, 2014.

[13] J. Alipoor, Y. Miura, and T. Ise, "Power System Stabilization Using Virtual Synchronous Generator with Alternating Moment of Inertia," IEEE J. Emerg. Sel. Top. Power Electron., vol. 03, no. 2, pp. 451-458, 2015.

[14] T. K. Vrana and C. Hille, “A novel control method for dispersed converters providing dynamic frequency response,” Electr. Eng., vol. 93, no. 4, pp. 217-226, 2011.

[15] S. D’Arco, J. A. Suul, and O. B. Fosso, “Control system tuning and stability analysis of Virtual Synchronous Machines," in IEEE Energy Conversion Congress and Exposition (ECCE), 2013, pp. 2664-2671.

[16] B. Zhang, X. Yan, D. Li, X. Zhang, J. Han, and X. Xiao, "Stable Operation and Small-Signal Analysis of Multiple Parallel DG Inverters Based on a Virtual Synchronous Generator Scheme,” Energies , vol. 11, no. 1. 2018.

[17] F. Gao and M. R. Iravani, “A control strategy for a distributed generation unit in grid-connected and autonomous modes of operation," IEEE Trans. Power Deliv., vol. 23, no. 2, pp. 850-859, 2008.

[18] S. M. Ashabani and Y. A. R. I. Mohamed, "A flexible control strategy for grid-connected and islanded microgrids with enhanced stability using nonlinear microgrid stabilizer," IEEE Trans. Smart Grid, vol. 3, no. 3, pp. 1291-1301, 2012. 
[19] H. Alatrash, A. Mensah, E. Mark, G. Haddad, and J. Enslin, "Generator emulation controls for photovoltaic inverters," IEEE Trans. Smart Grid, vol. 3, no. 2, pp. 996-1011, 2012.

[20] Y. Hirase, K. Abe, K. Sugimoto, and Y. Shindo, "A grid-connected inverter with virtual synchronous generator model of algebraic type," Electr. Eng. Japan (English Transl. Denki Gakkai Ronbunshi), vol. 184, no. 4, pp. 10-21, 2013.

[21] Y. Chen, R. Hesse, D. Turschner, and H. Beck, "Dynamic Properties of the Virtual Synchronous Machine (VISMA )," in Proc. ICREPQ, 2011.

[22] S. Wang, J. Hu, and X. Yuan, "Virtual synchronous control for grid-connected DFIG-based wind turbines," IEEE J. Emerg. Sel. Top. Power Electron., vol. 3, no. 4, pp. 932-944, 2015.

[23] K. Sakimoto, Y. Miura, and T. Ise, "Stabilization of a power system with a distributed generator by a Virtual Synchronous Generator function," in ICPE 2011-ECCE Asia, 2011, pp. 1498-1505.

[24] P. Mitra, L. Zhang, and L. Harnefors, "Offshore Wind Integration to a Weak Grid by VSC-HVDC Links Using Power-Synchronization Control : A Case Study,” IEEE Trans. Power Deliv., vol. 29, no. 1, pp. 453-461, 2014.

[25] M. Ashabani, F. D. Freijedo, S. Golestan, and J. M. Guerrero, "Inducverters: PLL-less converters with auto-synchronization and emulated inertia capability," IEEE Trans. Smart Grid, vol. 7, no. 3, pp. 1660-1674, 2016.

[26] Q. C. Zhong, P. Nguyen, Z. Ma, and W. Sheng, "Self-Synchronized Synchronverters : Inverters Without a Dedicated Synchronization Unit," IEEE Trans. Power Electron., vol. 29, no. 2, pp. 617-630, 2014.

[27] W. Zhang, D. Remon, J. Rocabert, et. al. "Frequency Support Properties of the Synchronous Power Control for Grid-Connected Converters," in IEEE Energy Conversion Congress and Exposition (ECCE), 2016, pp. 1-8.

[28] P. Rodriguez, I. Candela, J. Rocabert, and R. Teodorescu, "United States Patent Application Publication: Synchronous power controller for a generating system based on static power converters," US 2014/0049228 A1, Feb. 2012.

[29] N. Soni, S. Doolla, and M. C. Chandorkar, "Improvement of transient response in microgrids using virtual inertia," IEEE Trans. Power Deliv., 2013.

[30] B. Zhang, X. Yan, D. Li, X. Zhang, J. Han, and X. Xiao, "Stable Operation and Small-Signal Analysis of Multiple Parallel DG Inverters Based on a Virtual Synchronous Generator Scheme,” Energies , vol. 11, no. 1. 2018.

[31] P. Rodriguez, I. Candela, and A. Luna, "Control of PV generation systems using the synchronous power controller," in IEEE Energy Conversion Congress and Exposition (ECCE), 2013, pp. 993-998.

[32] John J. Grainger and W. D.Stevenson, Power System Analysis. McGraw-Hill, Inc, 1994.

[33] W. Wu, Y. Chen, A. Luo, L. Zhou, X. Zhou, L. Yang, Y. Dong, and J. M. Guerrero, “A Virtual Inertia Control Strategy for DC Microgrids Analogized with Virtual Synchronous Machines,” IEEE Trans. Ind. Electron., 2017. 